\title{
Effects of salt stress on proline content, expression of delta-1-pyrroline-5-carboxylate synthetase, and activities of catalase and ascorbate peroxidase in transgenic tobacco plants
}

\author{
ROYA RAZAVIZADEH and ALI AKBAR EHSANPOUR* \\ Department of Biology, Faculty of Sciences, University of Isfahan, Isfahan, Iran \\ *Correspondence: ehsanpou@yahoo.com
}

(Received on 18 March 2009; Accepted on 25 September 2009)

\begin{abstract}
In arid and semiarid regions, soil salinity limits crop production. Proline accumulation in transgenic plants results in increased stress tolerance, but the underlying mechanism was unclear. To elucidate it, effects of salt stress on the expression pattern of $\Delta^{1}$-pyrroline-5-carboxylate synthetase (P5CS), proline content, catalase (CAT), and ascorbate peroxidase (APX) activities were analyzed in transgenic tobacco (Nicotiana tabacum cv. Wisconsin). Transgenic tobacco plants containing CaMV $35 \mathrm{~S}$ promoter and the P5CS gene from moth bean (Vigna aconitifolia), linked to the NPTII gene, were cultured in vitro with or without $300 \mathrm{mM} \mathrm{NaCl}$. The expression pattern of P5CS was evaluated using semiquantitative RT-PCR (reverse transcription-polymerase chain reaction). Time-course experiments showed an increase in proline content after $4 \mathrm{~h}$ of the treatment. The level of P5CS transcripts was increased significantly in leaves and roots of transgenic plants after 24 and $48 \mathrm{~h}$ of treatment. This rise in transcripts was concomitant with the highest increase in proline content. In addition, CAT and APX activities increased under salt stress, and their highest activities were observed after 24 and $48 \mathrm{~h} \mathrm{of} \mathrm{NaCl}$ treatment. These results suggest that P5CS is an inducible gene regulating the activities of CAT and APX and the accumulation of proline in plants subjected to salt stress.
\end{abstract}

Keywords: tobacco, salt stress, proline, catalase, ascorbate peroxidase

\section{INTRODUCTION}

High salinity is the most important environmental factor causing osmotic stress and it negatively affects plant growth and productivity (PARVIz \& SATYAwATI 2008). To counteract this stress, plants accumulate organic osmolytes, such as proline and glycine betaine (CHINNUSAMY et al. 2005). These organic solutes protect plants from abiotic stress by osmotic adjustment, which helps in turgor maintenance, detoxification of reactive oxygen species (ROS), and stabilization of protein structure. Proline also acts as an antioxidant, stabilizes subcellular structures (membranes), and buffers cellular redox potential under stress (CHINNUSAMY et al. 2005). There are 2 alternative routes in proline biosynthesis in higher plants: L-ornithine and L-glutamate pathways. Under osmotic stress, the glutamate pathway predominates over ornithine pathway 
(PARVAiz \& SATYAWATi 2008). In plants, $\Delta^{1}$-pyrroline-5-carboxylate synthetase (P5CS) is a key enzyme in the proline biosynthetic pathway. P5CS is a bifunctional enzyme with both $\delta$-glutamyl kinase $(\mathrm{GK})$ and $\delta$-glutamyl phosphate reductase activities (MAGGIO et al. 2002). It has been documented that transgenic plants overexpressing the P5CS gene, increase the concentration of proline and are more resistant to both drought and salinity stresses (KISHOR et al. 1995). However, it was unclear whether proline accumulation in transgenic plants resulted in increased stress tolerance through osmotic adjustment or other mechanisms (SHARP et al. 1996).

Salinity induces oxidative stress in plants (XIONG \& ZHU 2002). Alleviation of oxidative damage by scavenging reactive oxygen species (ROS), with the use of antioxidant enzymes, is an important strategy of plants for increasing stress tolerance (Chinnusamy et al. 2005). There are several antioxidant enzymes involved in free radical scavenging. Superoxide dismutase (SOD), catalase (CAT), ascorbate peroxidase (APX), and peroxidase (POX) are the most important of them. Plant catalases are haem-containing tetrameric enzymes involved in the removal of hydrogen peroxide $\left(\mathrm{H}_{2} \mathrm{O}_{2}\right)$ during photorespiratory functions (CAnvin 1990, Guan \& Scandalios 1996), $\beta$-oxidation of fatty acids in germinating seeds (WILLEKENS et al. 1995), and abiotic stress conditions (WILLEKENS et al. 1995; Jithesh et al. 2006). Plants have evolved multiple CAT isozymes, which are encoded by members of a small gene family. It has been reported that plant catalases can be classified into 3 main classes. Class II catalases are mostly dicot catalases. Existing data on class II catalases suggest that they play an important role in stress responses in plants (JiTHESH et al. 2006). Ascorbate peroxidases are antioxidant enzymes performing the same general function as catalases, but unlike catalase they remove $\mathrm{H}_{2} \mathrm{O}_{2}$ by using ascorbate as a reductant (SHIGEOKA et al. 2002). Several studies have reported a large increase in CAT and APX activities after salt stress in rice (LEE et al. 2001), pea (HerNANDEZ et al. 2001), cotton (GossetT et al. 1994), and Thellungiella halophila (WANG et al. 2004). Transgenic tobacco (Nicotiana tabacum) plants overexpressing AtAPX targeted to the chloroplasts showed enhanced tolerance to salinity and oxidative stress. These pieces of evidence show that ROS detoxification is an important trait for salt tolerance of plants. Recent studies suggest a link between increased osmolyte content (e.g. proline) and decreased ROS production for improvement of salt tolerance (JITHESH et al. 2006). In Suaeda nudiflora, proline protects callus cells from membrane damage caused by free radicals during salt stress (CHERIAN \& REDDY 2003). Experiments in transgenic plants have been performed to confirm the protection offered by proline to $\mathrm{NaCl}$-induced oxidative stress (JiTHESH et al. 2006; Hong et al. 2000). A significantly lower level of malondialdehyde (a marker of free-radical production) was observed in proline-overproducing plants, as compared to wild-type plants. This suggests that concentrations of proline synthesized in transgenic plants provide a means to reduce the levels of free radicals generated during $\mathrm{NaCl}$ stress (HonG et al. 2000).

The aim of the present study was to evaluate salt stress effects on overexpression of the P5CS gene and relationship of proline content with CAT and APX activities over a time course in transgenic tobacco plants. This helped to elucidate the mechanism responsible for increased stress tolerance in proline-overproducing transgenic plants. 


\section{MATERIALS AND METHODS}

\section{Plant materials and treatment}

Transgenic tobacco plants (Nicotiana tabacum cv. Wisconsin) carrying the P5CS gene were used for this investigation. A coding sequence of the P5CS gene from moth bean (Vigna aconitifolia, GenBank Accession number M92276, (Hu et al. 1992) was digested with $M u l$ I and EcoR I, and ligated between the CaMV 35S promoter and Nos terminator in the pGA748 vector. The constructed pGAP5CS vector was introduced into Agrobacterium tumefaciens (LBA4404). This construct was kindly provided by Professor Cheol Ho Hwang, School of Bioresource Science, Dankook University, Cheonan, South Korea.

Transgenic tobacco plants overexpressing the P5CS gene were grown on MS medium (Murashige \& SKoog 1962) containing kanamycin $(25 \mathrm{mg} / \mathrm{l})$, and were kept in the growth chamber $(16 \mathrm{~h}$ light $/ 8 \mathrm{~h}$ dark $)$ at $25^{\circ} \mathrm{C}$ and $95 \%$ relative humidity. We transferred 18-20-day-old seedlings to MS medium with or without $300 \mathrm{mM} \mathrm{NaCl}$. Proline content and CAT and APX activities were measured in leaves and roots of salt-treated and untreated transgenic and nontransgenic tobacco plants after $0,4,8$, 12,24 , and $48 \mathrm{~h}$.

\section{Free proline}

Proline content was estimated using ninhydrin reaction (BATES et al. 1973). A small portion $(0.5 \mathrm{~g})$ of leaves or roots was homogenized with $10 \mathrm{ml}$ of $3 \%(\mathrm{w} / \mathrm{v})$ sulphosalicylic acid, and passed through Whatman filter paper no. 2. Then ninhydrin reagent $(2 \mathrm{ml})$ (Sigma) and glacial acetic acid $(2 \mathrm{ml})$ were added to $2 \mathrm{ml}$ of the filtered extract. The mixture was incubated at $100^{\circ} \mathrm{C}$ for $1 \mathrm{~h}$, and the reaction was terminated by placing it on ice. The reaction mixture was extracted with $4 \mathrm{ml}$ toluene, and absorption of chromophore was measured at $520 \mathrm{~nm}$, against toluene as blank, using spectrophotometer (Shimadzu UV-160, Japan). Proline content was calculated using L-proline (Sigma) as a standard curve.

\section{Reverse transcription-polymerase chain reaction ( $R T-P C R)$}

Total RNA was isolated from leaf tissue after $0,4,24$, and $48 \mathrm{~h}$ of salt treatment, using RNX Plus Kit (Cinnagen, Tehran, Iran) according to the manufacturer's protocol. First-strand cDNA was synthesized with $250 \mathrm{ng}$ of total RNA, using Revart Aid First strand cDNA synthesis KIT (Fermentas) according to the manufacturer's protocol. The reaction was achieved by incubating each sample at $70^{\circ} \mathrm{C}$ for $5 \mathrm{~min}$, placing on ice for $3-5 \mathrm{~s}$, and incubating at $37^{\circ} \mathrm{C}$ for $5 \mathrm{~min}$, followed by addition of reverse transcriptase and incubation at $42^{\circ} \mathrm{C}$ for $60 \mathrm{~min}$. The reaction was stopped by heating at $70^{\circ} \mathrm{C}$ for $10 \mathrm{~min}$. PCR amplification for the P5CS gene was performed in a total volume of $20 \mu \mathrm{l}$, containing $1 \mu \mathrm{l}$ of cDNA, for 39 cycles in a DNA thermal cycler. After an initial denaturation step of $94^{\circ} \mathrm{C}$ for $2 \mathrm{~min}$, each cycle included denaturation at $94^{\circ} \mathrm{C}$ for $30 \mathrm{~s}$, annealing for $30 \mathrm{~s}$ at $55^{\circ} \mathrm{C}$, and extension at $72^{\circ} \mathrm{C}$ for $30 \mathrm{~s}$, followed by a final extension step of $72^{\circ} \mathrm{C}$ for $5 \mathrm{~min}$. The RT-PCR reaction for the housekeeping 18S rRNA gene was performed in the same conditions as described above, to compare the amounts of different RNA samples. PCR amplification of $18 \mathrm{~S}$ 
rRNA cDNA was carried out in a total volume of $25 \mu 1$, containing $1 \mu 1$ of cDNA, for 45 cycles in the following conditions: initial denaturation at $94^{\circ} \mathrm{C}$ for $5 \mathrm{~min}$, followed by $90 \mathrm{~s}$ at $94^{\circ} \mathrm{C}, 30 \mathrm{~s}$ at $55^{\circ} \mathrm{C}, 45 \mathrm{~s}$ at $72^{\circ} \mathrm{C}$, and finally $7 \mathrm{~min}$ at $72^{\circ} \mathrm{C}$. PCR products were examined by $1 \%$ agarose gel. RT-PCR reactions were repeated twice, using 2 different cDNA samples.

The P5CS gene was amplified using forward (5'-GAG GCT ATT CGG CTA TGA CTG-3') and reverse (5'-ATC GGG AGC GGC GAT ACC GTA-3') primers. For amplification of the 18S rRNA gene (AJ236016) we used forward (5' - CTC AAC ACG GGA AAC TTA C-3') and reverse (5'-AGA CAA TCG CTC CAC CAA C-3') primers. The expression level of transcripts was quantified with Image $\mathrm{J}$ software (rsb.info.nih.gov/ij/docs/install/) and analyzed in 3 replicates.

\section{Enzyme extraction and activity assays}

A portion (100 mg) of transgenic and nontransgenic tobacco leaf or root was homogenized in $1 \mathrm{ml}$ of phosphate buffer saline (PBS) (pH 7.4), containing $8 \mathrm{~g}$ of NaCl, $0.2 \mathrm{~g}$ of $\mathrm{KCl}, 1.44 \mathrm{~g}$ of $\mathrm{Na}_{2} \mathrm{HPO}_{4}, 0.24 \mathrm{~g}$ of $\mathrm{KH}_{2} \mathrm{PO}_{4}$, and $1 \%$ polyvinylpyrrolidone. The homogenate was centrifuged at $4000 \mathrm{rpm}$ for $10 \mathrm{~min}$ at $4^{\circ} \mathrm{C}$, and the supernatant was used for CAT (EC 1.11.1.6) and APX (EC 1.11.1.11) activity assays.

CAT activity was assayed in a $1-\mathrm{ml}$ reaction mixture containing $50 \mathrm{mM}$ potas-

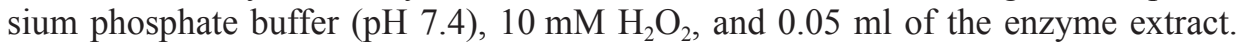
The subsequent decomposition of $\mathrm{H}_{2} \mathrm{O}_{2}$ was determined at $240 \mathrm{~nm}\left(\mathrm{E}=0.0394 \mathrm{mM}^{-1}\right.$ $\mathrm{cm}^{-1}$ ) (AEBI 1984), using a spectrophotometer (Shimadzu).

APX activity was determined in a $1-\mathrm{ml}$ reaction mixture containing $25 \mathrm{mM}$ potassium phosphate buffer ( $\mathrm{pH} 7.0), 0.5 \mathrm{mM}$ ascorbic acid, $0.2 \mathrm{mM}$ EDTA-4H, $0.1 \mathrm{mM} \mathrm{H}_{2} \mathrm{O}_{2}, 50 \mu \mathrm{l}$ of BSA, and $0.05 \mathrm{ml}$ of the enzyme extract. The subsequent decrease in ascorbic acid was determined at $290 \mathrm{~nm}\left(\mathrm{E}=2.8 \mathrm{mM}^{-1} \mathrm{~cm}^{-1}\right)$ (NAKANO \& AsADA 1981).

\section{RESULTS}

\section{Proline production}

Proline content was measured in leaves and roots of transgenic and nontransgenic tobacco plants after $0,4,8,12,24$ and $48 \mathrm{~h}$ of $\mathrm{NaCl}$ treatment (Fig. 1). The increase in proline content of leaves and roots was started after $4 \mathrm{~h}$ of $\mathrm{NaCl}$ treatment. However, the highest proline accumulation was observed after $48 \mathrm{~h}$ of treatment. In leaves of transgenic plants, proline content was significantly higher than in nontransgenic plants, except at $24 \mathrm{~h}$. The level of proline accumulation in leaves was significantly $(P<0.05)$ higher than in roots.

\section{Expression of the P5CS gene}

The transcript level of P5CS was measured in leaves of transgenic tobacco plants after $0,4,24$ and $48 \mathrm{~h}$ of treatment with $300 \mathrm{mM} \mathrm{NaCl}$ (Fig. 2A and C). The expression of P5CS was induced significantly $(P<0.05)$ after 24 and $48 \mathrm{~h}$ of $\mathrm{NaCl}$ treatment, as compared to 0 and $4 \mathrm{~h}$. No significant difference in expression level of the $18 \mathrm{~S}$ rRNA gene was observed after treatment (Fig. 2B). 



Fig. 1. Time course of proline content in leaves (A) and roots (B) of transgenic (white columns) and nontransgenic (black columns) tobacco seedlings treated with $300 \mathrm{mM} \mathrm{NaCl}$ for $0,4,8,12$, 24 , and $48 \mathrm{~h}$. Values are means $\pm \mathrm{SE}$ from 3 independent experiments. Asterisks indicate significant differences between transgenic and nontransgenic plants $(P<0.05)$ 

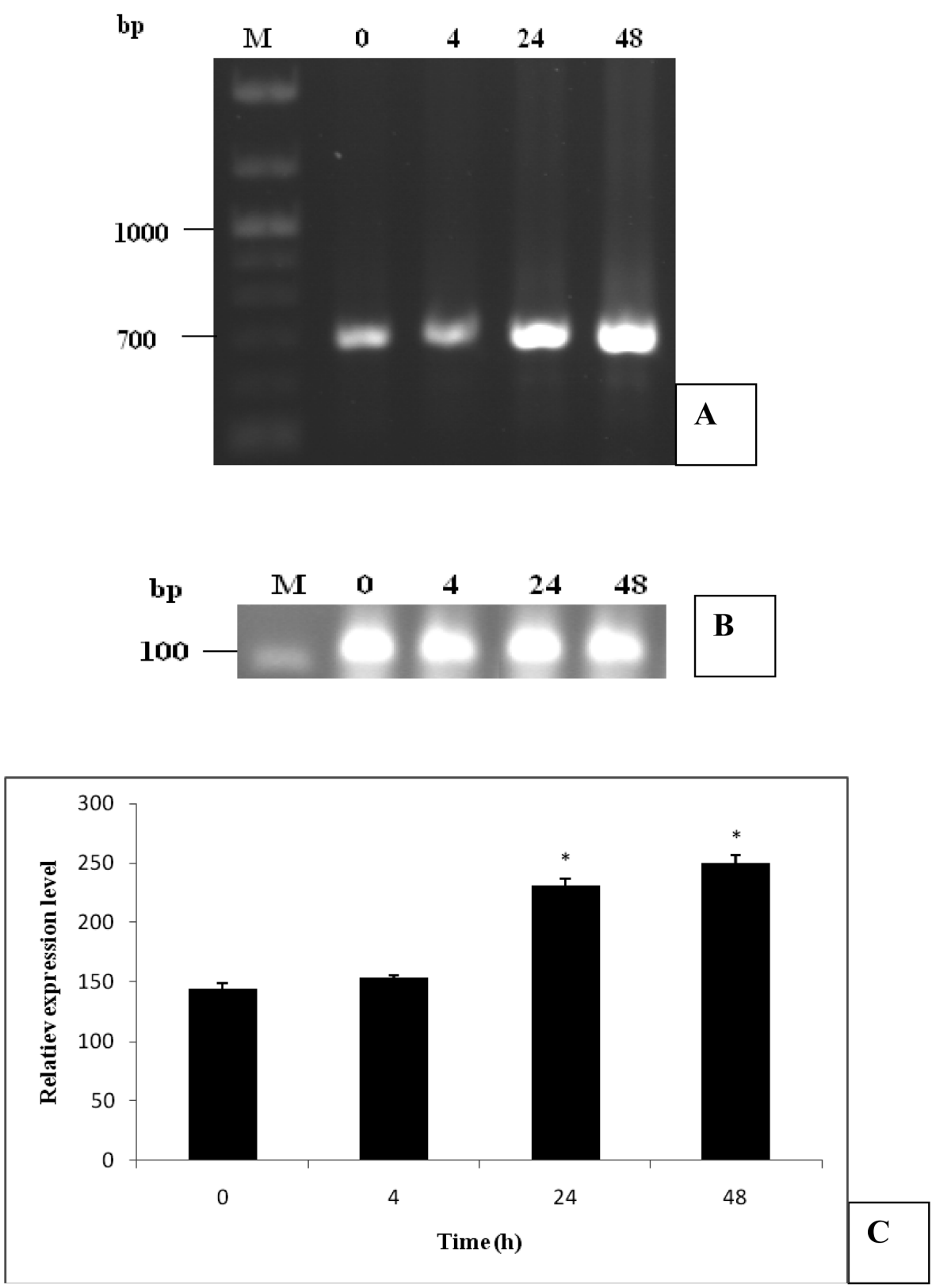

Fig. 2. Expression analysis of the P5CS gene (A) in response to $\mathrm{NaCl}$ treatment, and of $18 \mathrm{~S}$ rRNA as internal control (B) in leaves of transgenic tobacco plants treated with $300 \mathrm{mM} \mathrm{NaCl}$ for 0,4 , 24 , and $48 \mathrm{~h}$. Total RNA was isolated from young leaves of transgenic seedlings, and after reverse transcription, cDNA was used as template for PCR. Expression was quantified with Image J software (C). Product volumes are means \pm SE from 3 independent experiments. Asterisks indicate significant differences between control and salt-stressed plants $(* \mathrm{P}<0.05)$ 


\section{CAT activity}

The CAT activity increased after 4 and $8 \mathrm{~h}$ of $\mathrm{NaCl}$ treatment and then decreased at 24 and $48 \mathrm{~h}$ in transgenic leaves, in comparison to nontransgenic ones (Fig. 3A). When CAT activity was assayed in roots, transgenic plants showed a significant increase in CAT activity after 4, 8, 12, 24 and $48 \mathrm{~h}$ of treatment (Fig. 3B). The maxi-
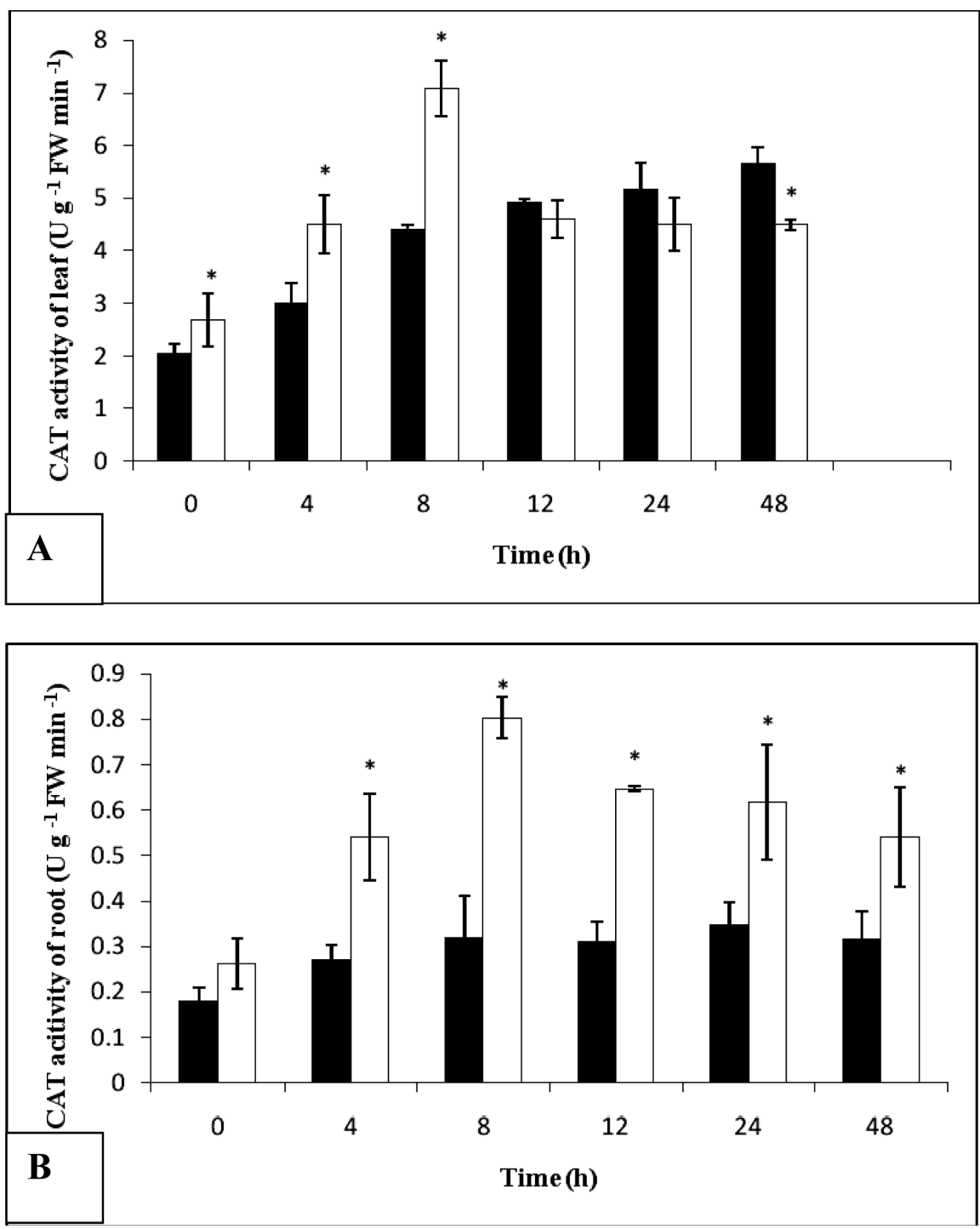

Fig. 3. Changes in catalase activity of leaves (A) and roots (B) of transgenic (white columns) and nontransgenic (black columns) tobacco seedlings treated with $300 \mathrm{mM} \mathrm{NaCl}$ for $0,4,8,12,24$, and $48 \mathrm{~h}$. Values are means \pm SE from 3 independent experiments. Asterisks indicate significant differences between transgenic and nontransgenic plants $(P<0.05)$ 
mum CAT activity was observed at $8 \mathrm{~h}$ in both leaves and roots of transgenic plants (Fig. 3A and B). The CAT activity in roots of transgenic and nontransgenic plants, without and with salt stress, was significantly $(P<0.05)$ lower than in leaves.
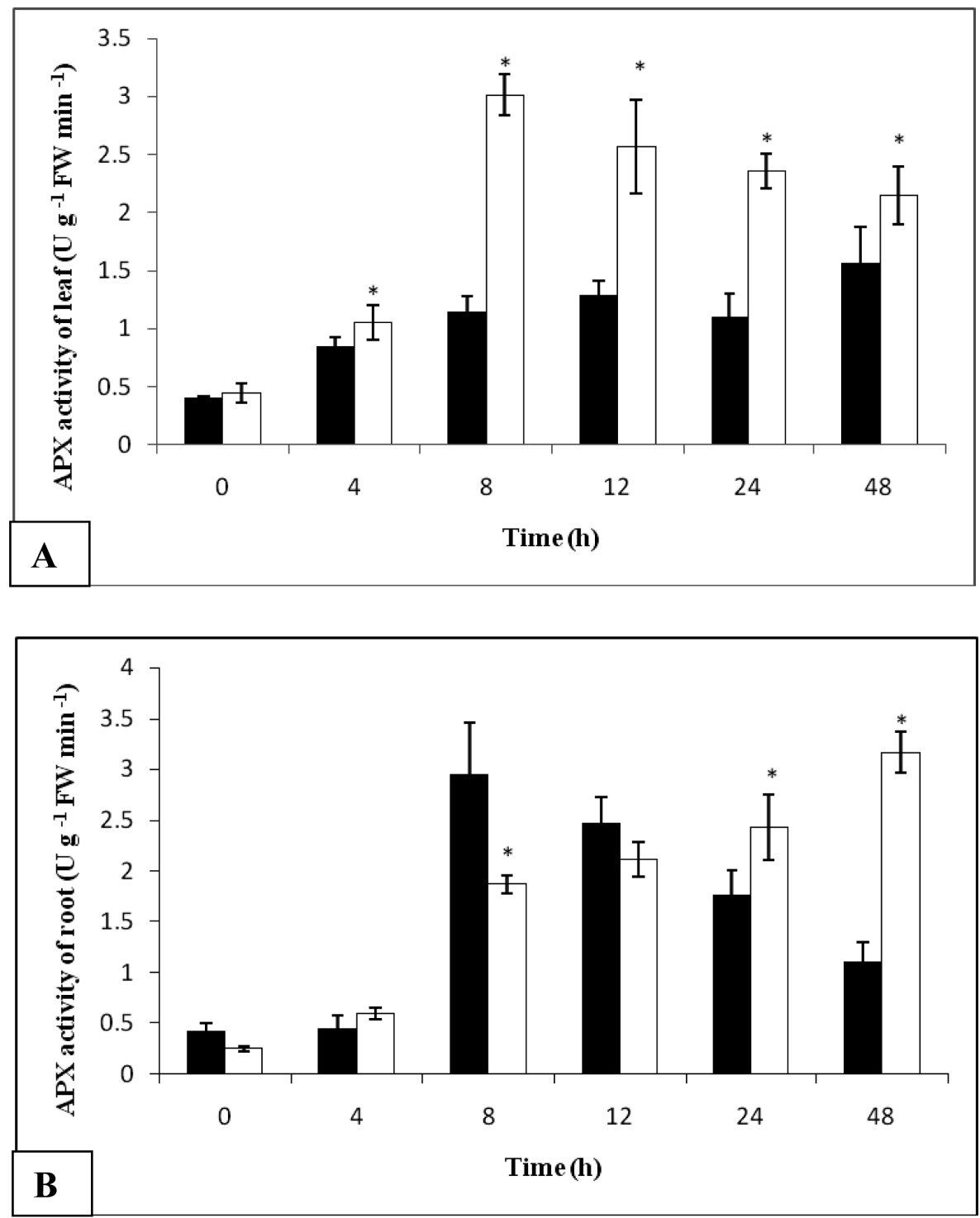

Fig. 4. Changes in ascorbate peroxidase activity of leaves (A) and roots (B) of transgenic (white columns) and nontransgenic (black columns) tobacco seedlings treated with $300 \mathrm{mM} \mathrm{NaCl}$ for 0 , $4,8,12,24$, and $48 \mathrm{~h}$. Values are means $\pm \mathrm{SE}$ from 3 independent experiments. Asterisks indicate significant differences between transgenic and nontransgenic plants $(P<0.05)$ 


\section{APX activity}

APX activity in transgenic leaves, in comparison with nontransgenic leaves, was increased significantly during all measurements except at time 0 in transgenic roots. The maximum APX activity was observed after $8 \mathrm{~h}$ of the treatment (Fig. 4A). APX activity was different in roots of salt-treated plants. After 24 and $48 \mathrm{~h}$ of the treatment, the APX activity in transgenic roots was significantly $(P<0.05)$ higher than in nontransgenic plants (Fig. 4B). In contrast to CAT activity, the difference between APX activity of roots and leaves was not significant $(P<0.05)$.

\section{DISCUSSION}

Osmoprotectants are of particular interest for improving abiotic stress tolerance of plants. The accumulation of proline under abiotic stress conditions has been studied in numerous plants (reviewed by VERBRUGGEN \& HERMANs 2008). The relationship between this trait and stress tolerance is not fully understood. In the Solanaceae, a moderate increase in proline content has been reported under stress conditions (MAGGIO et al. 2002). Our data show that proline was accumulated in leaves and roots of transgenic as well as nontransgenic plants. However, the accumulation of proline in roots and leaves of transgenic plants was much higher than in nontransgenic plants. It is clear that the higher amount of proline in transgenic plants is due to overexpression of the P5CS gene. Under osmotic stress, proline stabilizes proteins, membranes, and subcellular structures (VANRENSBURG et al. 1993), and protects cellular functions by scavenging ROS (BOHNERT \& SHEN 1999). It seems that proline may play the same role in improvement of tobacco plants overexpressing the P5CS gene.

It was postulated that glutamate pathway of proline synthesis is predominant under osmotic stress in plants (Roosens et al. 2002). When proline synthesis is induced by osmotic stress, the P5CS gene has a role as a rate-limiting enzyme in the proline biosynthetic pathway in plants. A correlation between transcript level of the P5CS gene and proline content was shown in a number of plants. In the present study, the P5CS transcript level was upregulated after 24-48 $\mathrm{h}$. The time course analysis of proline content showed similar patterns to RT-PCR results. These results indicate that alternations in the levels of P5CS mRNA are likely responsible for the altered proline content in transgenic plants. It is well established that several stresses - such as drought, salt and cold stress - result in accumulation of proline, due to upregulation of the P5CS gene (KisHor et al. 2005).

Several roles have been proposed for the massive stress-induced accumulation of proline in plants, including osmotic adjustment, membrane protection, free radical scavenging, and redox buffering (reviewed by Verbruggen \& Hermans 2008; KISHOR et al. 2005). Elevated levels of proline, caused by overexpression of P5CS, can confer enhanced tolerance to salt stress in plants (HAN \& HwANG 2003). It has been reported that transgenic plants overexpressing the P5CS gene produced a high level of the antioxidant enzymes and synthesized more proline than the controls. The transformants tolerated salt stress and showed enhanced root biomass under greenhouse conditions. The increase in proline in transgenic plants suggests that P5CS activity is the rate-limiting step (KISHOR et al. 2005). In addition to synthesis, proline 
catabolism and transport are thought to control endogenous proline accumulation in plants. The feedback inhibition by proline as an end product was shown to be lost under stress (ZHANG et al. 1995). Similar patterns of salt tolerance due to overexpression of the P5CS gene have also been reported in transgenic rice and transgenic wheat (ZHU et al. 1998). Enhanced salt tolerance was achieved also when the same gene was introduced in carrot cell lines, green microalgae, and wheat (HAN \& HwANG 2003; SiripornAdUlsil et al. 2002; SAWAHEL \& HASSAN 2002). The transgenic algae had $80 \%$ higher proline levels, grew more rapidly in toxic cadmium concentrations, and bound 4-fold more cadmium than wild-type cells. The promoter of the P5CS gene was described as stress-inducible in transgenic Arabidopsis subjected to water stress (ZhANG et al. 1997). Similar results have been reported when the P5CS gene isolated from rice was introduced in the same plant (HuR et al. 2004). The transgenic plant was found to be salt-inducible which is also essential for salt and cold tolerance (DJiLiANOv et al. 2005).

Abiotic stresses, including salt stress, induce ROS accumulation that causes oxidative damage to membrane lipids, proteins, and nucleic acids (SMIRNOFF 1993), Gomez et al. 1999; Hernandez et al. 2001). Plants employ nonenzymatic antioxidants (e.g. ascorbate, glutathione, $\alpha$-tocopherol, and carotenoids) and detoxifying enzymes - such as superoxide dismutase, catalase, and ascorbic peroxidase - to combat oxidative stress. The increasing activity of detoxifying enzymes is probably enhanced by ROS under abiotic stresses. Transgenic plants overexpressing ROS-scavenging enzymes, such as superoxide dismutase (reviewed by Alscher et al. 2002), ascorbate peroxidase (WANG et al. 1999), and glutathione $S$-transferase/glutathione peroxidase (RoxAs et al. 1997, 2000), have an increased tolerance to osmotic, thermal, and oxidative stresses. Similarly to our findings, overexpression of the tobacco NtGST/ $G P X$ gene (encoding a bifunctional enzyme with both glutathione $S$-transferase and glutathione peroxidase activity) in transgenic tobacco plants has improved salt and chilling-stress tolerance, because of enhanced ROS scavenging and prevention of membrane damage (RoxAs et al. 2000).

Our data show that salt stress induced CAT and APX enzymes in leaves and roots of transgenic plants much higher than in nontransgenic plants, with some variations in different time points after salt stress. In our study we are speculating that there is a link between the rise in P5CS transcripts, production of proline as an osmolyte, and activities of CAT and APX. The increase in P5CS transcripts in transgenic plants was associated with the accumulation of proline in leaves and roots. On the other hand, salt stress increased CAT and APX activities in leaves and roots. Since a major role of these antioxidant enzymes is scavenging of produced ROS due to salt stress, it can be concluded that proline accumulation and antioxidant activities may cooperate with each other for more tolerance to salt stress. In plants, proline also scavenges singlet oxygen and free radicals that induce damages, and performs an important role in protection of proteins against denaturation (AliA et al. 1991). Increased proline content and improved tolerance to abiotic stresses, in salt-stressed calli of Suaeda nudiflora as a halophyte plant, suggested that proline protects the callus cells from membrane damage caused by free radicals during salt stress (CHERIAN \& REDDY 2003). In Pancratium maritimum L., salt stress resulted in inhibition of the 
antioxidant enzymes catalase and peroxidase, but activities of these enzymes were also maintained significantly higher in the presence of proline. It is concluded that proline improves the salt-tolerance of Pancratium maritimum L. Exogenous proline has been reported to protect plants under stress (KHEDR et al. 2003). OKuma et al. (2000) found that exogenous proline improved the growth of salt-stressed tobacco cell cultures, and the improvement was attributed to the role of proline as an osmoprotectant for enzymes and membranes against salt inhibition, rather than as a compatible solute. NANJO et al. (1999) reported on transgenic Arabidopsis plants with reduced pyrroline-5-carboxylate synthase activity, the rate-limiting enzyme in proline synthesis from glutamate, were unable to grow on saline media, but feeding plants with L-proline could increase their ability to withstand salinity. It has also been reported that proline is involved in the synthesis of key proteins that are necessary for stress responses (KHEDR et al 2003).

It can be concluded that overexpression of the P5CS gene and proline accumulation in association with CAT and APX activities increase salt tolerance in tobacco plants via cooperation with different pathways.

\section{REFERENCES}

Aebi H. 1984. Catalase in vitro. Methods Enzymol. 105: 121-126.

Alia P. S. P., Pardha Saradhi P., Mohanty P. 1991. Proline enhances primary photochemical activities in isolated thylakoid membranes of Brassica juncea by arresting photoinhibitory damage. Biochem. Biophys. Res. Commun. 181: 1238-1244.

Alscher R. G., Erturk N., Heath L. S. 2002. Role of superoxide dismutases in controlling oxidative stress in plants. J. Exp. Bot. 53:1331-1341.

Bates L., WaldRen R. P., Tear I. P. 1973. Rapid determination of free proline for water stress studies. Plant Soil. 39: 205-207.

Bohnert H. J., Shen B. 1999. Transformation and compatible solutes. Sci. Hortic. 78: 237-260.

CANVIN D. T. 1990. Photorespiration and $\mathrm{CO}_{2}$ concentrating mechanisms. In: Plant Physiology, Biochemistry, and Molecular Biology (Dennis D. T., Turpin D. H, Eds), pp. 253-273, Longman Scientific and Technical, Harlow.

Cherian S., RedDy M. P. 2003. Evaluation of $\mathrm{NaCl}$ tolerance in the callus cultures of Suaeda nudiflora. Moq. Biol. Plantarum. 46: 193-198.

Chinnusamy V., Jagendorf A., Zhu J. K. 2005. Understanding and improving salt tolerance in plants. Crop Sci. 45: 437-448.

Dullianov D., Georgieva T., Moyankova D., Atanassov A., Shinozaki K., Smeeken S. C. M., Verma D. P. S., Murata N. 2005. Improved abiotic stress tolerance in plants by accumulation of osmoprotectants: gene transfer approach. Biotechnol. \& Biotechnol. Special Issue. 63-75.

Gomez J. M., Hernandez J. A., Jimenez A., Del Rio L. A., Seville F. 1999. Differential response of antioxidative enzymes of chloroplast and mitochondria to long term $\mathrm{NaCl}$ stress of pea plants. Free Radical Res. 31: 11-18.

Gosset D. R., Millhollon E. P., Lucas M. C. 1994. Antioxidant response to $\mathrm{NaCl}$ stress in salttolerant and salt-sensitive cultivars of cotton. Crop Sci. 34: 706-714.

Guan L., Scandalios J. G. 1996. Molecular evolution of maize catalases and their relationship to other eukaryotic and prokaryotic catalases. J. Mol. Evol. 42: 570-579.

Han K. H., Hwang C. H. 2003. Salt tolerance enhanced by transformation of a P 5 CS gene in carrot. J. Plant Biotechnol. 5: 149-153. 
Hernandez J. A., Ferrer M. A., Jimenez A., Barcelo A. R., Seville F. 2001. Antioxidant systems and $\mathrm{O}_{-} 2 / \mathrm{H} 2 \mathrm{O} 2$ production in the apoplast of pea leaves. Its relation with salt-induced necrotic lesions in minor veins. Plant Physiol. 127: 817-83.

Hong Z., Lakkineni K., Zhang Z., Verma D. P. S. 2000. Removal of feedback inhibition of delta (1)-pyrroline-5-carboxylate synthetase results in increased proline accumulation and protection of plants from osmotic stress. Plant Physiol. 122: 1129-1136.

Hu Ch. A., Delauney A. J., Verma D. P. S. 1992. A bifunctional enzyme ( $\Delta^{1}$ pyrroline-5-carboxylate synthetase) catalyzes the first two steps in proline biosynthesis in plants. Plant Biol. 89: 9354-9358.

Hur J., Jung K. H., Lee C. H., An G. H. 2004. Stress-inducible OsP5CS2 gene is essential for salt and cold tolerance in rice. Plant Sci. 167: 417-426.

Jithesh M. N., Prashanth S. R., Sivaprakash K. R., Parida A. K. 2006. Antioxidative response mechanisms in halophytes: their role in stress defence. J. Genet. 85: 237-255.

Khedr A. H. A., Abbas M. A., Wahid A. A. A., Quick W. P., Abogadallah G. M. 2003. Proline induces the expression of salt stress responsive proteins and may improve the adaptation of Pancratium maritimum L. to salt stress. J. Exp. Bot. 54: 2553-2562.

Kishor P. B. K., Hong Z., Miao G. H., Hu C. A. A., Verma D. P . S. 1995. Overexpression of [delta]pyrroline-5- carboxylate synthetase increases proline production and confers osmotolerance in transgenic plants. Plant Physiol. 108: 1387-1394.

Kishor P. B. K., Sangam S., Amrutha R. N., Sri Laxmi P., Naidu K. R., Rao K. R., Theripan P., Sreenivasula N. 2005. Regulation of proline biosynthesis, degradation, uptake and transport in higher plants: Its implication in plant growth and abiotic stress tolerance. Current Science. 108: 427-437.

Lee D. H., Kim Y. S., LeE C. B. 2001. The inductive responses of the antioxidant enzymes by salt stress in rice (Oryza sativa L.). J. Plant Physiol. 158: 737-745.

Maggio A., Miyazakil S., Veronese P., Tomomichi Fujta T., Ibeas J., Damszl B., Narasimhan M. L., Hasegawal P. M., Joly R. J., Bressan R. A. 2002. Does proline accumulation play an active role in stress-induced growth reduction? The Plant Journal. 31: 699-712.

Murashige T., Skoog F. 1962. A revised medium for rapid growth and bioassays with

tobacco cultures. Physiol. Plantarum. 159: 473-479.

NAKAno Y., Asada A. 1981. Hydrogen peroxide is scavenged by ascorbate- specific peroxidase in spinach chloroplast. Plant Cell Physiol. 22: 867-880.

Nanjo T., Kobayashi M., Yoshiba Y., Yukika S., Keishiro W., Tsukaya H., Kakubari Y., YamaguchiSHINOZAKI K., SHINOZAKI K. 1999. Biological functions of proline in morphogenesis and osmotolerance revealed in antisense transgenic Arabidopsis thaliana. The Plant Journal. 18: $185-193$.

Okuma E., Soeda K., Tada M., Murata Y. 2000. Exogenous proline mitigates the inhibition of growth of Nicotiana tabacum cultured cells under saline conditions. Soil Sci. Plant Nutr. 46: 257-263.

Parvaiz A., Satyawati S. 2008. Salt stress and phyto-biochemical responses of plants - a review. Plant Soil Environ. 54: 89-99.

Roosens N. H., Bitar F. A., Loenders K., Angenon G., Jacobs M. 2002. Overexpression of ornithine- $\delta$-aminotransferase increases proline biosynthesis and confers osmotolerance in transgenic plants. Mol. Breeding. 9: 73-80.

Roxas V.P., Smith R. K., Allen E. R., Allen R. D. 1997. Over expression of glutathione S-transferase /glutathione peroxidase enhances the growth of transgenic tobacco seedlings during stress. Nat. Biotechnol. 15: 988-991.

Roxas V. P., Lodhi S. A., Garrett D. K., Mahan J. R., Allen R. D. 2000. Stress tolerance in transgenic tobacco seedlings that overexpress glutathione S-transferase/glutathione peroxidase. Plant Cell Physiol. 41: 1229-1234.

Sawahel W. A., Hassan A. H. 2002. Generation of transgenic wheat plants producing high levels of the osmoprotectant proline. Biotechnol. Lett. 24: 721-725. 
Sharp R. E., Boyer J. S., Nguyen H. T., Hsiao T. C. 1996. Genetically engineered plants resistant to soil drying and salt stress: how to interpret osmotic relations. Plant Physiol. 110: 1051-1053.

Shigeoka S., Ishikawa T., Tamoi M., Miyagawa Y., Takeda T., Yabuta Y., Yoshimura K. 2002. Regulation and function of ascorbate peroxidase isoenzymes. J. Exp. Bot. 53: 1305-1319.

Siripornadulsil S., Traina S., Verma D. P. S., Sayre R. T. 2002. Proline action on heavy metal detoxification in microalgae. Plant Cell. 14: 2837-2847.

SMIRNOFF N. 1993. The role of active oxygen in the response of plants to water deficit and desiccation. New Phytol. 125:27-58.

Vanrensburg L., Kruger G. H., Kruger H. 1993. Proline accumulation as drough- tolerance selection criterion: Its relationship to membrane integrity and chloroplast ultra-structure in Nicotiana tabacum. L. J. Plant Physiol. 141: 188-194.

Verbruggen N., Hermans C. 2008. Proline accumulation in plants: a review. Amino Acids. 35: $753-759$.

Wang J., Zhang H., Allen R. D. 1999. Overexpression of an Arabidopsis peroxisomal ascorbate peroxidase gene in tobacco increases protection against oxidative stress. Plant Cell Physiol. 40: 725-732.

Wang Z. L., Li H. P., Fredricksen M., Gong Z. Z., Kim C. S., Zahng C. Q. 2004. Expressed sequence tags from Thellungiella halophila, a new model to study plant salt tolerance. Plant Sci. 166: 609-616.

Willekens H., Inz'E D., Van Montagu M., Van Camp W. 1995. Catalase in plants. Mol. Breeding. 1: 207-228.

Xiong L., Zhu J. K. 2002. Molecular and genetic aspects of plant responses to osmotic stress. Plant Cell Environ. 25: 131-139.

Zhang C. S., Lu Q., Verma D. P. S. 1995. Removal of feedback inhibition of delta1-pyrroline-5carboxylate synthetase, a bifunctional enzyme catalyzing the first two steps of proline biosynthesis in plants. J. Biol. Chem. 270: 20491-20496.

Zhang C. S., Lu Q., Verma D. P. S. 1997. Characterization of D1- pyrroline-5-carboxylate synthetase gene promoter in transgenic Arabidopsis thaliana subjected to water stress. Plant Sci.129: 81-89.

Zhu B., Su J., Chang M., Verma D. P. S., Fan Y. L., Wu R. 1998. Overexpression of a $\Delta^{1}$-pyrroline5-carboxylate synthetase gene and analysis of tolerance to water- and salt-stress in transgenic rice. Plant Sci. 139: 41-48. 